inequalities through improved systems and infrastructure.

Following early consultations another focus area was added: the allocation of health resources.

It is expected that the project will produce a number of resources:

- the NSW Health and Equity Statement, which will outline a set of practical steps to be taken over the next five years to tackle health inequality;

- a targeted literature review in each of the five original strategy areas;

- a report on the findings of the interviews with the CEOs and the workshops.

The project is expected to be completed and the statement released by the end of 2001 .

\section{SUMMARY}

The NSW Health and Equity Statement is an early and significant step in the journey to improve health and reduce the gap between people with the poorest and best health in NSW.

The statement complements Healthy People 2005 and has the support of the Director-General, the Departmental
Executive and the CEOs of urban and rural Area Health Services. Although the statement will focus on what the NSW health system can do to reduce inequalities during the next five years, over time it will be important to extend the work to the social determinants of health that operate outside the usual responsibilities of the health system.

\section{REFERENCES}

1. NSW Department of Health. Greater Sydney Metropolitan Health Plan.

2. Public Health Division. The Health of the People of NSWReport of the Chief Health Officer 2000. Sydney: NSW Department of Health, 2000.

3. Dixon J. A National R\&D Collaboration on Health and Socioeconomic Status for Australia. First Discussion Paper. Canberra: National Centre for Epidemiology and Population Health, Australian National University, 1999.

4. Acheson D et al. The Independent Inquiry into Inequalities in Health Report. London: The Stationery Office, 1998.

5. Wilkinson R and Marmot M (editors). Social Determinants of Health: The Solid Facts. Copenhagen: World Health Organization Regional Office for Europe, 1998.

6. Royal Australasian College of Physicians. For richer, for poorer, in sickness and in health. Sydney: Royal Australasian College of Physicians, 1998.

7. Public Health Division. Healthy People 2005. Sydney: NSW Department of Health, 2000. 嵒

\title{
MANAGING A TOBACCO CONTROL PROGRAM IN NSW CORRECTIONAL CENTRES, 1999-2001
}

\section{Niyi Awofeso and Michael Levy \\ Corrections Health Service}

\section{Suzi Morris}

\section{NSW Department of Corrective Services}

Tobacco smoking remains the leading cause of premature death and the number one preventable public health problem in Australia and in most developed countries. ${ }^{1}$ Unlike the trends in the general population, where a decreasing prevalence has been observed over the past 30 years, ${ }^{2}$ smoking prevalence among inmates of Australian correctional centres remains consistently high, with over two-thirds of the inmate population being regular smokers. ${ }^{3}$ This article describes a tobacco control program implemented in NSW correctional facilities from May 1999 to April 2001. The future directions of the program are also discussed.

\section{PROGRAM STRUCTURE AND ACTIVITIES}

The Tobacco Control Program (TCP) is jointly planned and monitored by the Corrections Health Service (CHS) and the Department of Corrective Services (DCS). At each correctional facility, the program is implemented by alcohol and other drug workers from DCS, and clinic nurses from CHS. The aims of the TCP are to:
- reduce the uptake of smoking;

- reduce tobacco consumption;

- promote smoking cessation;

- protect non-smokers from environmental tobacco smoke ${ }^{4}$

- provide viable accommodation options for nonsmoking inmates.

The TCP promotes non-smoking as the social norm while ensuring that its tobacco control activities are antismoking without being anti-smoker. It is not a tobacco prohibition program.

Between May 1999 and April 2001, the following activities were undertaken as part of the TCP:

- raising awareness about tobacco and health;

- prevalence studies of tobacco use among inmates;

- an attitudinal survey of staff and inmates;

- a pilot program of smoking cessation and support.

\section{RAISING AWARENESS ABOUT TOBACCO AND HEALTH}

Historically, correctional facilities have been neglected in tobacco control initiatives, at both state and national 
levels. For example, correctional centres were not mentioned in the NSW Tobacco and Health Strategy $1995-1999,5$ or the National Tobacco Strategy 19992003. ${ }^{6}$ To raise awareness about tobacco and health in correctional centres, the issue of tobacco control was made a priority health issue in the CHS performance agreement with the NSW Department of Health. Also, tobacco control was made a regular theme at joint CHS-DCS public health planning meetings; and key figures in the area of Australian tobacco policy were approached to advise on guidelines for a tobacco control initiative. A publication highlighting the inadequacy of the attention given to tobacco control programs in correctional centres was published in an international peer-reviewed journal in $1999,{ }^{7}$ and a presentation on tobacco control in NSW correctional centres was given at the 12th Annual Health Promotion Conference. ${ }^{8}$ Inmates designed two varieties of an anti-tobacco poster, which were distributed to all correctional facilities. Since 2001, nurses and alcohol and other drug workers have been counselling inmates on the health effects of tobacco.

\section{PREVALENCE STUDIES ON TOBACCO USE AMONG INMATES}

A prevalence study of tobacco use was undertaken in NSW correctional facilities in 2000. The study found that, on average, 72 per cent of inmates were regular smokers, which is more than three times the national average of 22 per cent for the same year. Smoking prevalence was higher in metropolitan prisons, among female inmates, and among inmates in psychiatric wards. ${ }^{9}$ The data have provided a valuable advocacy tool for tobacco control activities in NSW correctional facilities.

\section{ATTITUDINAL SURVEY OF STAFF AND INMATES}

In 2000, a self-administered attitudinal survey on current prison tobacco policies was conducted among inmates, DCS staff, and CHS staff. Analysis of survey responses indicated agreement on the following issues:

- inmates and/or staff of DCS and CHS should not be totally restricted from smoking within NSW correctional facilities;

- further restrictions on smoking in correctional facilities would result in increased tension between staff and inmates;

- further restrictions on smoking would be acceptable if help (counselling and pharmacotherapy) were offered to inmates and staff who want to quit smoking.

Although most inmates supported the lifting of all current restrictive tobacco policies, ${ }^{10}$ most CHS and DCS staff opposed such a policy change. The majority of inmates thought that restrictions on tobacco would violate their civil liberties, while the CHS and DCS staff were equivocal on this point. Current tobacco control programs in NSW correctional centres, such as smoking cessation support, were guided by the results of the survey.

\section{PILOT SMOKING CESSATION AND SUPPORT PROGRAM}

Two pilot programs on smoking cessation among inmates, incorporating free nicotine replacement therapy, were commenced in June 2000. Nine female inmates and 15 male inmates enrolled on the program. After six months, four of the male participants had ceased smoking completely, while all but 11 of the remaining 20 participants had substantially reduced the average quantity smoked. The evaluation of the program provided an indication of the context-specific issues that needed to be addressed when statewide implementation commenced.

\section{DISCUSSION}

Inmates of NSW correctional centres have the same attributes as other smokers in the community, ${ }^{3}$ and tend to:

- come from lower socioeconomic groups;

- have a lower education;

- possess a number of lifestyle factors such as drug and alcohol abuse, poor diets, and decreased physical activity. ${ }^{11}$

Several factors make the implementation of tobacco control programs in NSW correctional centres particularly difficult:

- unfulfilled expectations of a 'trickle-down effect' of policies adapted from the general population;

- 'prison culture', which makes tobacco smoking accepted as the norm by both staff and inmates of correctional centres;

- the apparently 'beneficial effects' of nicotine in stimulating 'reward centres' of the brain, which is an important coping mechanism for inmates who are secluded in cells for between 12-17 hours daily; ${ }^{12}$

- reluctance by correctional and health authorities to allocate adequate resources for addressing the problem of tobacco use in correctional centres.

The prevalence of tobacco use in correctional centres in Australia and most developed countries remains high, in contrast to the remarkable success of reducing smoking prevalence in the general community. ${ }^{9,13}$ However, it is possible to build the capacity of tobacco control programs in correctional centres, in the hope of eventually reducing smoking prevalence within correctional centres to community levels. Future initiatives include: enhanced awareness campaigns, a repeat of prevalence studies and attitudinal surveys, the establishing of designated smokefree wings and cells, and the expansion of smoking cessation and support programs to four other correctional facilities during 2001.

\section{REFERENCES}

1. English DR, Holman CDJ, Milne E, et al. The quantification of drug-caused morbidity and mortality in Australia, 1995 
edition. Canberra: Commonwealth Department of Human Services and Health, 1995.

2. Australian Bureau of Statistics. Australian social trends, 2000. Canberra: ABS, 2000; 73-76.

3. Butler T. New South Wales Prison Inmates' Health Survey. Sydney: Corrections Health Service, 1997.

4. Edwards R, Brown JS, Hodgson P, Reed D, Wallace B. An action plan for tobacco control at the regional level. Public Health 1999; 113: 165-170.

5. NSW Department of Health. Tobacco and Health Strategy, 1995-1999. Sydney: NSW Department of Health, 1995.

6. Commonwealth Department of Health and Aged Care. National Tobacco Strategy, 1999 to 2002-2003: A framework for action. Canberra: Commonwealth Department of Health and Aged Care, 1999.

7. Awofeso N. Controlling tobacco use in prisons. Int J Tuberc Lung Dis 1999; 3: 547-8.
8. Awofeso N. Tobacco control in New South Wales Prisons: Translating Advocacy into Programs and Change. 12th Health Promotion Conference, Melbourne, October 2000 (unpublished).

9. Awofeso N, Testaz R, Wyper S, Morris S. Smoking prevalence in New South Wales prisons, 2000. Tobacco Control, 2001; 10: 84-5.

10. Department of Corrective Services. Smoke-Free Work Environment (Correctional Facilities) Policy, 17 May 1989, Sydney (unpublished).

11. Klesges RC, Haddock CK, Chang CF, Talcott WG, Lando HA. The association of smoking and the cost of military training. Tobacco Control 2001; 10: 43-47.

12. Hughes JR. Why does smoking so often produce dependence? A somewhat different view. Tobacco Control 2001; 10: 62-64.

13. Editorial. Cigarette smoking bans in county jails-Wisconsin, 1991. MMWR 1992; 41: 101-3.

\section{IDENTIFYING WORK-RELATED INJURY AND DISEASE IN ROUTINELY COLLECTED NSW HOSPITALISATION DATA}

\section{David Muscatello \\ Epidemiology and Surveillance Branch NSW Department of Health}

\section{Rebecca Mitchell}

Health Promotion Branch

NSW Department of Health

Occupational disease and injury has been estimated to account for nearly three per cent of the global burden of disease. ${ }^{1}$ In NSW in the 1998-99 financial year, there were 38,069 workers' compensation cases reported to the National Occupational Health and Safety Commission. However, this figure is an under-estimation of the true incidence of occupational disease and injury in NSW, because it includes only cases resulting in compensation under NSW workers' compensation legislation, it only includes cases involving absences from work of five days or more, and because self-employed people are not generally covered for workers' compensation. ${ }^{2}$ This article describes an analysis of the NSW Inpatient Statistics Collection (ISC) to identify work-related hospitalisations, and comments on its potential for monitoring occupational disease and injury in NSW.

\section{METHODS}

The NSW ISC is a census of separations from NSW public and private hospitals, which is routinely collected by the NSW Department of Health. Clinical coders at each hospital or health service code medical record information for each hospital admission episode and enter the data into a database that is periodically uploaded to the central data repository held at the NSW Department of Health. Information collected includes patient demographics, payment status, diagnoses and clinical procedures. External causes are recorded for hospitalisations following injury or poisoning and can be recorded for other conditions.

For the period used for this analysis (1999-00 financial year), diagnoses, external causes and procedures in the ISC were coded according to the International Statistical Classification of Diseases and Related Health Problems, 10th Revision, Australian Modification (ICD-10-AM), first edition. ${ }^{3}$ In the first edition of the ICD-10-AM, the fifth character of the ICD code for external cause classifies the activity being undertaken by the patient when the injury or illness occurred. An activity code of ' 2 ' indicates 'working for income'. ${ }^{3}$ A principal diagnosis and up to 20 additional diagnoses were coded, and up to three external causes could be coded.

A fourth character was also available for coding in the ICD-10-AM (1st edition) to code the place where the injury or illness occurred. We did not use this fourth character because it only identifies a subset of workrelated places, such as industrial or construction areas. It does not permit identification of whether the person was engaged in a work-related activity at that place, and it is possibly less likely to be noted on the medical record than the activity the person was engaged in.

Hospital separations from the 1999-00 financial year ISC database were identified as occupationally related if they had any of:

- a first external cause coded combined with an activity when injured of 'working for income' (ICD-10-AM 